\title{
Carotid intima-media thickness in individuals with and without type 2 diabetes: a reproducibility study
}

\author{
Louise Lundby-Christensen ${ }^{1 *}$, Thomas P Almdal ${ }^{1 \dagger}$, Bendix Carstensen ${ }^{1 \dagger}$, Lise Tarnow ${ }^{1 \dagger}$, Niels Wiinberg ${ }^{2 \dagger}$
}

\begin{abstract}
Background: The use of carotid intima-media thickness (carotid IMT) as a surrogate marker of cardiovascular disease is increasing and the method has now also been applied in several trials investigating patients with type 2 diabetes (T2D). Even though knowledge about methodology is of highest importance in order to make accurate power calculations and analyses of results, no reproducibility studies have been performed in this group of patients. The aim of this study was to quantify the variability of the measurement of carotid IMT in individuals with and without T2D.
\end{abstract}

Methods: We used B-mode ultrasound and a computerized software programme (MIA vascular tools) for analysis of carotid IMT. Measurement of carotid IMT in the far wall of the common carotid artery (CCA) was done for 30 patients with T2D and 30 persons without T2D. The examinations were done by two different sonographers and two different readers on two separate days in order to quantify sonographer-, reader-, and day-to-day variability.

Results: Comparisons of measurement of carotid IMT in CCA between sonographers (sonographer variability) resulted in limits of agreement (LOA) from -0.18 to $0.13 \mathrm{~mm}$ for patients with T2D and -0.12 to $0.10 \mathrm{~mm}$ for persons without T2D. This means, that a second scanning of the same person with 95\% probability would be within this interval of the first scanning. Comparisons between readers assessing the same scanning (reader variability) resulted in LoA from -0.05 to $0.07 \mathrm{~mm}$ and -0.04 to $0.05 \mathrm{~mm}$ respectively. LoA of the day-to-day variability was -0.13 to $0.18 \mathrm{~mm}$ and -0.09 to $0.18 \mathrm{~mm}$ respectively. This corresponds to coefficients of variations (CV) of the sonographer- and day-to-day variability of $10 \%$ in patients with T2D and $8 \%$ in persons without T2D. The CV of the reader variability was $4 \%$ and $3 \%$ respectively.

Conclusion: Measurement of carotid IMT in the CCA can be determined with good and comparable reproducibility in both patients with T2D and persons without T2D. These findings support the use of carotid IMT in clinical trials with T2D patients and suggest that the numbers of patients needed to detect a given difference will be the same whether the patients have T2D or not.

\section{Background}

Determination of carotid intima-media thickness (carotid IMT) is a generally accepted research method for detection and quantification of subclinical cardiovascular disease (CVD). It is based on the combined thickness of the tunica intima and tunica media of the carotid artery wall and is measured by B-mode ultrasound. A number of epidemiological studies reports that increased carotid

\footnotetext{
* Correspondence: Ilch@steno.dk

† Contributed equally

${ }^{1}$ Steno Diabetes Center, Niels Steensens vej 2-4, 2820 Gentofte, Denmark

Full list of author information is available at the end of the article
}

IMT is a good predictor of future CVD such as myocardial infarction, stroke and death from CVD. Furthermore carotid IMT correlates well with clinically established CVD and the Framingham Score[1-5]. Based on the existing evidence from trials with statins, carotid IMT fulfils the three generally accepted requirements for a surrogate marker[6]. In addition, the measurement is non-invasive, inexpensive, readily applicable and carries virtually no risk for the patient. Therefore, carotid IMT has now become an established surrogate marker of CVD in clinical trials to evaluate the efficacy of interventions with statins, antihypertensives, aspirin and

\section{() Biomed Central}


antidiabetic medications [7-12]. The primary advantages of using a surrogate marker instead of hard outcome measures such as myocardial infarction, stroke and death are smaller study populations, shorter study duration and thereby reduced financial costs.

In general, knowledge about research methodology is of highest importance and as stated by Fleiss in 1986 "The most elegant design of a clinical study will not overcome the damage caused by unreliable or imprecise measurements"[13]. This applies obviously also to measurement of carotid IMT. The technique, by which carotid IMT is determined, consists of two steps: The first step is the "scanning procedure" i.e. ultrasound scanning of the carotid artery, with storage of pictures/dynamic sequences and the second step is the "reading procedure" i.e. the following measurement of carotid IMT using a specialized software technique. Even though the variability of the technique like this is influenced by both the scanning procedure and by the following reading procedure, many reproducibility studies have only taken the variability of the reading procedure into account which does not reflect the total variability [14-16]. Furthermore, no methodological studies have explicitly evaluated the reproducibility in patients with type 2 diabetes (T2D) even though the method has now also been increasingly applied in clinical trials with diabetes patients [10-12,17-19].

Patients with T2D have a two to fourfold increased incidence of CVD compared to persons without diabetes $[20,21]$, which is also reflected by an increased carotid IMT in T2D patients [22-24]. Earlier studies have suggested that the variability of the measurement of carotid IMT increases with increasing carotid IMT[25]. Hence, it could be argued that the variability is increased in T2D patients compared to persons without T2D, but this has not been assessed systematically.

The purpose of this study was to quantify the variability between sonographers, between readers and between days of the measurement of carotid IMT in the far wall of the common carotid artery (CCA) in patients with $\mathrm{T} 2 \mathrm{D}$ and persons without T2D.

\section{Methods}

\section{Patients}

Sixty persons participated in this study; 30 patients with T2D and 30 persons without T2D.

\section{Visits}

All participants paid two visits within two weeks (visit A and B) at Steno Diabetes Center, Copenhagen, Denmark. At each visit patients were scanned by two different sonographers (sonographer $\mathrm{X}$ and $\mathrm{Y}$ ), to enable assessment of the day-to-day variability and the sonographer variability (table 1 ).
Table 1 Scanning and reading procedure for every participant for the measurement of mean carotid IMT

\begin{tabular}{|c|c|c|c|}
\hline Visit & Sonographer & Reader & Replicate \\
\hline \multirow[t]{8}{*}{$\bar{A}$} & $x$ & $x$ & 1 \\
\hline & & $x$ & 2 \\
\hline & & y & 1 \\
\hline & & $y$ & 2 \\
\hline & Y & $x$ & 1 \\
\hline & & $x$ & 2 \\
\hline & & $y$ & 1 \\
\hline & & y & 2 \\
\hline \multirow[t]{8}{*}{ B } & $x$ & $x$ & 1 \\
\hline & & $x$ & 2 \\
\hline & & $y$ & 1 \\
\hline & & y & 2 \\
\hline & Y & $x$ & 1 \\
\hline & & $x$ & 2 \\
\hline & & y & 1 \\
\hline & & $y$ & 2 \\
\hline
\end{tabular}

Every participant performed two visits ( $A$ and $B$ ). At every visit they were scanned twice by each of the sonographers $X$ and $Y$, and every scanning was read twice (replicate 1 and 2 ) by each of the two readers ( $x$ and $y$ ).

\section{Scanning procedure}

After 10 minutes of rest in a supine position blood pressure was measured at the left upper arm whereupon the scanning was performed using a General Healthcare (GE) logic 9 with a 9 linear $(8 \mathrm{MHz})$ or a 12 linear $(12 \mathrm{MHz})$ probe. The choice of probe depended on the most appropriate probe to the person; however, the same probe with the same frequency was used for the same person at every scanning. All examinations were carried out in a dark, quiet and temperature-controlled room.

With the head in a slightly bended position towards the opposite site of the one being scanned the ultrasound transducer was placed in an angle of $90^{\circ}$ of the vessel wall (to obtain parallel ecco lines of the intima and media in both near and far wall). First a rough cross sectional scanning was made from the proximal part of common carotid artery (CCA) throughout the bifurcation to the internal carotid artery and the external carotid artery to localise possible plaques or stenoses. The transducer was turned and a longitudinal scanning was made in the CCA with storage of the dynamic sequence for the following reading procedure to measure carotid IMT. The depth of the scan was adjusted and the transmit focus zone set at the optimal level to show the best possible image of the far wall of the CCA. A segment of the artery was magnified using a resolution box and the grey scale image adjusted to identify a distinct lumen-intima and media-adventitia interface of the artery wall. Then, 5 seconds of the ultrasound image was digitally recorded on a computer for later measurements of the carotid IMT. This procedure 
was made first on the right CCA and afterwards on the left CCA.

\section{Reading procedure}

For the border detection and calculation of the carotid IMT, we used specialized software (vascular tools 5, Medical Imaging Applications, Iowa, USA). First, the region of interest was defined as a segment of the CCA far wall devoid of focal plaques and spanning 5-10 $\mathrm{mm}$ with a centre $10 \mathrm{~mm}$ proximal to the bulb. In this region (= reading frame) the software identifies the lumen/intima and the media/adventitia borders and calculates the distance in between, i.e. the carotid IMT. The resolution of the ultrasound picture is 10 pixels $/ \mathrm{mm}$. The frequency of the picture is 15 pictures per second during five seconds. The final average carotid IMT on a $10 \mathrm{~mm}$ segment of the vessel wall is thus based on approximately 600 automated calculations during the 5 seconds. IMT was finally calculated as the mean IMT of the left and right CCA.

\section{Data}

For each patient we obtained four scanning results, two from each of the two visits (visit A and B, table 1).

Each of these were read twice by each of the two readers (reader $\mathrm{X}$ and $\mathrm{y}$ ) to measure inter- and intra-reader variability. The readers $(x, y)$ were the same persons as the sonographers $(X, Y)$. For each reading, the mean CCA of the left and right side were summed and averaged to yield the average mean carotid IMT resulting in a total of 16 values of average mean carotid IMT from each participant, classified by visit, sonographer, reader and replicate of reading (table 1). Replicates were considered exchangeable within each combination of visit, sonographer and reader.

\section{Statistical analysis}

We computed limits of agreement (LoA) and made Bland-Altman plots between all pairs of the 8 combinations of visit, sonographer and reader (figure 1). Replicates were randomly permuted for this comparison. These analyses were performed separately for measurements on patients with T2D and persons without T2D.

Here we report the uncertainty of the measurements as standard deviation of the mean absolute difference of the pairwise comparisons (SD (diff)), LoA on the absolute scale $(\mathrm{mm})$ as well as coefficient of variation $(\mathrm{CV})$ calculated as the SD of the differences of the log-transformed values. The LoA is the $95 \%$ prediction interval for the difference between results from two different combinations of visit, sonographer and reader, i.e. there is a $95 \%$ probability that the difference between two measurements will be in this interval. Depending on which combinations of visit, sonographer and reader are compared, different components of the variations are included; this is indicated in the Bland-Altman plots too
The study complied with the Declaration of Helsinki and was approved by the Regional Ethical Committee (region of Copenhagen journal number H-A-2007-0126).

\section{Results}

Of the 60 participants, two were excluded as the values of carotid IMT could not be obtained because of widespread atherosclerosis/plaques in the CCA. They (a man and a woman) had both had T2D for more than 15 years and clinically established CVD. Hence, 58 participants (28 patients with T2D and 30 persons without T2D) as characterised in table 2 were included in the analysis.

Mean carotid IMT in the far wall CCA in patients with T2D was $0.800 \pm 0.131 \mathrm{~mm}$ (mean $\pm \mathrm{SD}$ ). $50 \%$ of the patients with T2D were diagnosed with microalbuminuria (albumin-to-creatinin ratio $30-300 \mathrm{mg} / \mathrm{g}$ in $\geq$ two of three consecutive urine samples). Significantly higher values of carotid IMT were found in the 14 patients with microalbuminuria $(0.867 \mathrm{~mm} \pm 0.122)$ as compared to the 14 patients with normoalbuminuria $(0.733 \mathrm{~mm} \pm 0.106, \mathrm{p}<$ $0.005)$ despite no difference in age (62.1 years \pm 7.1 vs. $64.7 \pm 8.3, \mathrm{p}=0.4)$ or duration of T2D (15.8 years \pm 8.4 vs. $16.9 \pm 7.3, \mathrm{p}=0.7)$. In persons without T2D mean carotid IMT was $0.679 \pm 0.105 \mathrm{~mm}$. Nearly all patients with T2D were treated with simvastatin $40 \mathrm{mg}$ (96\%) whereas this was the case for only a very little proportion of the healthy persons (10\%). 96\% of the patients with T2D received antihypertensive treatment in terms of angiotensin converting enzyme inhibitors (ACEi, 39\%), angiotensin II receptor blockers (ARB, 54\%), $\beta$-blockers (11\%), diuretics (68\%) and/or calcium channel blockers (CCB, 32\%). Only two persons without T2D received antihypertensive treatment (ARB and diuretic respectively). Mean systolic blood pressure among patients with T2D was $132 \pm 19$ mmHg compared to $126 \pm 13 \mathrm{mmHg}$ among persons without T2D. Mean diastolic blood pressure was $77 \pm 9$ $\mathrm{mmHg}$ and $77 \pm 8 \mathrm{mmHg}$ respectively.

Glucose lowering therapies were given as follows: $11 \%$ received diet only, $25 \%$ received oral antidiabetics (OAD's, i.e. metformin \pm sulfonylurea) only, $64 \%$ received insulin (either long-acting (32\%), rapid-acting (11\%) and/or biphasic insulin (32\%).

The scatter plots and Bland-Altman plots with LoA indicated are shown in Figure 1, in blue for healthy persons and red for patients with T2D. Overall, there were no systematic difference between any of the combinations of day, sonographer and reader.

\section{Variability of measurement of carotid IMT in patients with T2D}

When different scanning results were assessed (sonographer variability), the LoA were -0.18 to $0.13 \mathrm{~mm}$. This means, that a second scanning of the same person with 95\% probability would be within this interval of the first 


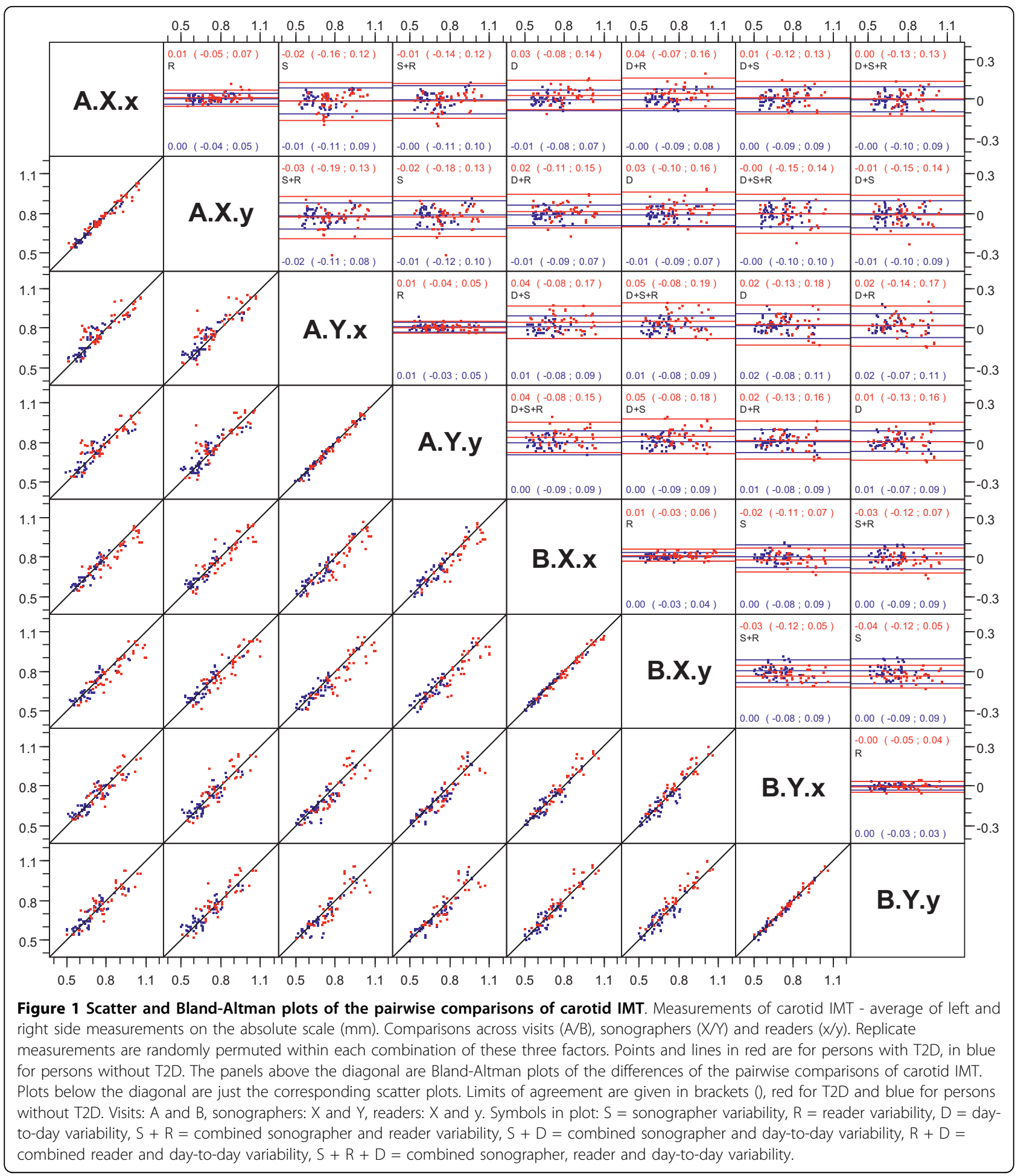

scanning. (Figure 1; LoA for T2D patients indicated by red numbers and lines, sonographer variability marked by "s"). The SD (diff) was $0.078 \mathrm{~mm}$. When the same scanning's were assessed by different readers (reader variability), the limits of agreement were -0.05 to 0.07 $\mathrm{mm}$ and the SD (diff) was $0.030 \mathrm{~mm}$. When comparing scanning's made by the same sonographer and read by the same reader but assessed on two different days (dayto-day variability) the limits of agreement were -0.13 to $0.18 \mathrm{~mm}$ and the SD (diff) was $0.075 \mathrm{~mm}$ (Figure 1). 
Table 2 Characteristics of participants (\%/mean \pm SD)

\begin{tabular}{|c|c|c|}
\hline & $\begin{array}{l}\text { Patients with } \\
\text { T2D }\end{array}$ & $\begin{array}{c}\text { Persons without } \\
\text { T2D }\end{array}$ \\
\hline n & 28 & 30 \\
\hline Age (years) & $63.4 \pm 7.8$ & $54.4 \pm 10.3$ \\
\hline Men (\%) & 68 & 47 \\
\hline Diabetes duration (years) & $16 \pm 8$ & 0 \\
\hline Smokers (\%) & 21 & 10 \\
\hline BMI $(\mathrm{kg} / \mathrm{m} 2)$ & $32.7 \pm 4.5$ & $26.4 \pm 3.6$ \\
\hline Microalbuminuria (\%) & 50 & 0 \\
\hline Prevalent CVD (\%) & 21 & 0 \\
\hline Total cholesterol (mmol/l) & $3.76 \pm 0.71$ & $5.10 \pm 1.06$ \\
\hline HDL cholesterol (mmol/l) & $1.33 \pm 0.39$ & $1.55 \pm 0.33$ \\
\hline LDL cholesterol (mmol/l) & $1.76 \pm 0.57$ & $2.94 \pm 0.93$ \\
\hline Triglycerides (mmol/l) & $1.45 \pm 0.55$ & $1.33 \pm 0.57$ \\
\hline Treatment with statins (\%) & 96 & 10 \\
\hline $\mathrm{HbA1c}(\%)$ & $7.75 \pm 1.04$ & $5.52 \pm 0.22$ \\
\hline $\begin{array}{l}\text { Therapeutic methods for T2D: } \\
\text { Diet only/OAD/insulin/OAD } \\
\text { +insulin (\%) }\end{array}$ & $11 / 14 / 50 / 25$ & \\
\hline Systolic blood pressure $(\mathrm{mmHg})$ & $132 \pm 19$ & $126 \pm 13$ \\
\hline Diastolic blood pressure $(\mathrm{mmHg})$ & $77 \pm 9$ & $77 \pm 8$ \\
\hline Antihypertensive treatment (\%) & 96 & 7 \\
\hline $\begin{array}{l}\text { Therapeutic method for } \\
\text { hypertension: } \\
\text { ACEi/ARB/ß-blockers/diuretics/ } \\
\text { CCB (\%) }\end{array}$ & $39 / 54 / 11 / 68 / 32$ & 0/3/0/3/0 \\
\hline Mean carotid IMT (mm) & $0.800 \pm 0.131$ & $0.679 \pm 0.105$ \\
\hline
\end{tabular}

OAD: Oral antidiabetics, ACEi: angiotensin-converting enzyme inhibitor, ARB: angiotensin II receptor blocker, CCB: calcium channel blocker

\section{Variability of measurement of carotid IMT in persons without T2D}

When different scanning results were assessed (sonographer variability), the limits of agreement were -0.12 to $0.10 \mathrm{~mm}$ and the SD (diff) was $0.055 \mathrm{~mm}$ (figure 1). When the same scanning's were assessed by different readers (reader variability), the limits of agreement were -0.04 to $0.05 \mathrm{~mm}$ and the SD (diff) was $0.023 \mathrm{~mm}$. When comparing scanning's made by the same sonographer and read by the same reader but assessed on two different days (day-to-day variability) the limits of agreement were -0.09 to $0.18 \mathrm{~mm}$ and the SD (diff) was $0.050 \mathrm{~mm}$.

The coefficient of variation (CV) as measured by the SD of the log-transformed values was $10 \%$ between sonographers and between days (10\% for patients with T2D and $8 \%$ for persons without T2D) and $4 \%$ between readers ( $4 \%$ for patients with T2D and 3\% for persons without T2D).

\section{Discussion}

The use of carotid IMT has been increasingly used in trials investigating patients with T2D. The existing knowledge about reproducibility of this method is based on very heterogeneously populations including either no or relatively few patients with $\mathrm{T} 2 \mathrm{D}[15,16]$. With regard to future clinical diabetes research further knowledge about reproducibility of this method is required. In this methodological study we have explicitly evaluated the reproducibility of the method in patients with T2D and persons without T2D and we have accurately pointed out the main sources and sizes of variability. The study shows that carotid IMT can be determined with good and comparable reproducibility in both patients with $\mathrm{T} 2 \mathrm{D}$ and healthy persons.

The patients with T2D participating in this study had a mean diabetes duration of $16 \pm 8$ years, $50 \%$ had microalbuminuria, $21 \%$ had clinical established CVD and the mean age was $63,4 \pm 7,8$ years which confirms that we deal with a group of patients with advanced disease. In contrast, the persons without T2D were younger (54.4 \pm 10,3 years) and had no clinical established CVD. The main source of variability in the measurement of carotid IMT was found in the scanning procedure with a CV of $10 \%$ and $8 \%$ for patients with T2D and persons without T2D respectively. This variability corresponds well with the sonographer variability reported in other studies performed in persons without T2D or in some cases appears to be of even smaller magnitude [25-27]. The day-to-day variability was identical to the sonographer variability for both patients with T2D and persons without T2D (CV of $10 \%$ and $8 \%$ respectively) which likewise is in agreement with earlier studies in normoglycaemic individuals[28]. Only a minor source of variability was found in the reading procedure ( $\mathrm{CV}$ of $4 \%$ and $3 \%$ respectively) as reported earlier in persons without T2D[16]. So even though the patients with T2D in this study had an advanced disease, were approximately 9 years older, had higher BMI, higher systolic blood pressure and a higher proportion of males, the variability of the measurement of carotid IMT were nearly identical to the persons without T2D. It should be noted, however, that this study only used two sonographers, so it could be argued, that more sonographers would increase the sonographer variability. However, as the variability between scanning results by the same sonographer from different days (day-to-day variability) is of the same order of magnitude as the variability between different sonographers on the same day (sonographer variability), it is unlikely that this would be the case.

In addition, we found a significant increase in carotid IMT independent of age and duration of diabetes in the T2D patients with microalbuminuria compared to the patients with normoalbuminuria. Accordingly, earlier studies have found a significant association between carotid IMT and diabetic nephropathy measured as either microalbuminuria (elevated ACR) and/or decreased estimated glomerular filtration rate (eGFR)[29-31]. 


\section{Conclusions}

In conclusion, this study demonstrates that measurement of carotid IMT can be performed in patients with T2D without markedly increasing the variability of the measurement as compared to persons without T2D. The major source of variability is found in the scanning procedure, which has nearly identical variability as the day-to-day variability, whereas very little variability is found in the following reading procedure.

Thus, given the present results studies using carotid IMT as outcome will be subject to nearly the same variability related to methodology whether they are performed in patients with T2D or in persons without. These results justify the use of carotid IMT in trials with T2D patients and suggest that the numbers of patients needed to detect a given difference in a clinical trial will be the same whether the patients have T2D or not.

\author{
Acknowledgements \\ We thank Birthe Nielsen and Lotte Pietraszek for their valuable technical \\ support with the ultrasound scanning and analyses. This study was \\ supported by a clinical research grant from Steno Diabetes Center A/S, \\ Gentofte, Denmark.
}

\section{Author details}

${ }^{1}$ Steno Diabetes Center, Niels Steensens vej 2-4, 2820 Gentofte, Denmark. ${ }^{2}$ Frederiksberg Hospital, dept. of clinical physiology and nuclear medicine, Nordre Fasanvej 57-59, 2000 Frederiksberg, Denmark.

\section{Authors' contributions}

LLC, TPA, LT and NW conceived of the study and participated in its design, coordination and helped to draft the manuscript. BXC participated in the design, helped to draft the manuscript and performed the statistical analyses. All authors read and approved the final manuscript.

\section{Competing interests}

The authors declare that they have no competing interests.

Received: 8 June 2010 Accepted: 20 August 2010

Published: 20 August 2010

\section{References}

1. Bots ML, Hoes AW, Koudstaal PJ, Hofman A, Grobbee DE: Common carotid intima-media thickness and risk of stroke and myocardial infarction: the Rotterdam Study. Circulation 1997, 96:1432-1437.

2. Chambless LE, Folsom AR, Clegg LX, Sharrett AR, Shahar E, Nieto FJ, Rosamond WD, Evans G: Carotid wall thickness is predictive of incident clinical stroke: the Atherosclerosis Risk in Communities (ARIC) study. American Journal of Epidemiology 2000, 151:478-487.

3. O'Leary DH, Polak JF, Kronmal RA, Manolio TA, Burke GL, Wolfson SK Jr: Carotid-artery intima and media thickness as a risk factor for myocardial infarction and stroke in older adults. Cardiovascular Health Study Collaborative Research Group. N Engl J Med 1999, 340:14-22.

4. Touboul PJ, Labreuche J, Vicaut E, Amarenco P, on behalf of the GENIC Investigators: Carotid Intima-Media Thickness, Plaques, and Framingham Risk Score as Independent Determinants of Stroke Risk. Stroke 2005, 36:1741-1745.

5. Yamasaki Y, Kodama M, Nishizawa H, Sakamoto K, Matsuhisa M, Kajimoto Y, Kosugi K, Shimizu Y, Kawamori R, Hori M: Carotid intima-media thickness in Japanese type 2 diabetic subjects: predictors of progression and relationship with incident coronary heart disease. Diabetes Care 2000, 23:1310-1315.
6. Boissel JP, Collet JP, Moleur P, Haugh M: Surrogate endpoints: a basis for a rational approach. Eur J Clin Pharmacol 1992, 43:235-244.

7. Bots ML, Palmer MK, Dogan S, Plantinga Y, Raichlen JS, Evans GW, O'Leary DH, Grobbee DE, Crouse I Jr: Intensive lipid lowering may reduce progression of carotid atherosclerosis within 12 months of treatment: the METEOR study. J Intern Med 2009, 265(6):698-707.

8. Crouse JR III, Raichlen JS, Riley WA, Evans GW, Palmer MK, O'Leary DH, Grobbee DE, Bots ML, for the METEOR Study Group: Effect of Rosuvastatin on Progression of Carotid Intima-Media Thickness in Low-Risk Individuals With Subclinical Atherosclerosis: The METEOR Trial. JAMA: The Journal of the American Medical Association 2007, 297:1344-1353.

9. Howard BV, Roman MJ, Devereux RB, Fleg JL, Galloway JM, Henderson JA, Howard WJ, Lee ET, Mete M, Poolaw B, Ratner RE, Russell M, Silverman A, Stylianou M, Umans JG, Wang W, Weir MR, Weissman NJ, Wilson C, Yeh F, Zhu J: Effect of lower targets for blood pressure and LDL cholesterol on atherosclerosis in diabetes: the SANDS randomized trial. JAMA: The Journal of the American Medical Association 2008, 299:1678-1689.

10. Katakami N, Yamasaki Y, Hayaishi-Okano R, Ohtoshi K, Kaneto H, Matsuhisa M, Kosugi K, Hori M: Metformin or gliclazide, rather than glibenclamide, attenuate progression of carotid intima-media thickness in subjects with type 2 diabetes. Diabetologia 2004, 47:1906-1913.

11. Kodama M, Yamasaki Y, Sakamoto K, Yoshioka R, Matsuhisa M, Kajimoto Y, Kosugi K, Ueda N, Hori M: Antiplatelet Drugs Attenuate Progression of Carotid Intima-Media Thickness in Subjects with Type 2 Diabetes. Thrombosis Research 2000, 97:239-245.

12. Matsumoto K, Sera Y, Abe Y, Tominaga T, Yeki Y, Miyake S: Metformin attenuates progression of carotid arterial wall thickness in patients with type 2 diabetes. Diabetes Res Clin Pract 2004, 64:225-228.

13. Fleiss $\mathrm{L}$ : The design and analysis of clinical experiments. John Wiley and sons, Inc, New York 1986.

14. Gepner AD, Korcarz CE, Aeschlimann SE, LeCaire TJ, Palta M, Tzou WS, Stein $\mathrm{JH}$ : Validation of a carotid intima-media thickness border detection program for use in an office setting. J Am Soc Echocardiogr 2006, 19:223-228.

15. Lim TK, Lim E, Dwivedi G, Kooner J, Senior R: Normal Value of Carotid Intima-Media Thickness-A Surrogate Marker of Atherosclersosis: Quantitative Assessment by B-Mode Carotid Ultrasound. Journal of the American Society of Echocardiography 2008, 21:112-116.

16. Touboul PJ, Vicaut E, Labreuche J, Belliard JP, Cohen S, Kownator S, PithoisMerli I: Design, baseline characteristics and carotid intima-media thickness reproducibility in the PARC study. Cerebrovasc Dis 2005, 19:57-63.

17. Langenfeld MR, Forst T, Hohberg C, Kann P, Lubben G, Konrad T, Fullert SD Sachara C, Pfutzner A: Pioglitazone decreases carotid intima-media thickness independently of glycemic control in patients with type 2 diabetes mellitus: results from a controlled randomized study. Circulation 2005, 111:2525-2531.

18. Yokoyama H, Katakami N, Yamasaki Y: Recent advances of intervention to inhibit progression of carotid intima-media thickness in patients with type 2 diabetes mellitus. Stroke 2006, 37:2420-2427.

19. Hosomi N, Mizushige K, Ohyama H, Takahashi T, Kitadai M, Hatanaka Y, Matsuo H, Kohno M, Koziol JA: Angiotensin-converting enzyme inhibition with enalapril slows progressive intima-media thickening of the common carotid artery in patients with non-insulin-dependent diabetes mellitus. Stroke 2001, 32:1539-1545.

20. Almdal T, Scharling $H$, Jensen JS, Vestergaard $H$ : The independent effect of type 2 diabetes mellitus on ischemic heart disease, stroke, and death: a population-based study of 13,000 men and women with 20 years of follow-up. Arch Intern Med 2004, 164:1422-1426.

21. Booth GL, Kapral MK, Fung K, Tu JV: Relation between age and cardiovascular disease in men and women with diabetes compared with non-diabetic people: a population-based retrospective cohort study. Lancet 2006, 368:29-36.

22. Bonora E, Kiechl S, Oberhollenzer F, Egger G, Bonadonna RC, Muggeo M, Willeit J: Impaired glucose tolerance, Type II diabetes mellitus and carotid atherosclerosis: prospective results from the Bruneck Study. Diabetologia 2000, 43:156-164.

23. Niskanen L, Rauramaa R, Miettinen H, Haffner SM, Mercuri M, Uusitupa M: Carotid artery intima-media thickness in elderly patients with NIDDM and in nondiabetic subjects. Stroke 1996, 27:1986-1992. 
24. Lee CD, Folsom AR, Pankow JS, Brancati FL: Cardiovascular events in diabetic and nondiabetic adults with or without history of myocardial infarction. Circulation 2004, 109:855-860.

25. de Groot E, van Leuven SI, Duivenvoorden R, Meuwese MC, Akdim F, Bots ML, Kastelein JJ: Measurement of carotid intima-media thickness to assess progression and regression of atherosclerosis. Nat Clin Pract Cardiovasc Med 2008, 5:280-288.

26. Meuwese MC, de GE, Duivenvoorden R, Trip MD, Ose L, Maritz FJ, Basart DC, Kastelein JJ, Habib R, Davidson MH, Zwinderman AH, Schwocho LR, Stein EA: ACAT inhibition and progression of carotid atherosclerosis in patients with familial hypercholesterolemia: the CAPTIVATE randomized trial. JAMA: The Journal of the American Medical Association 2009, 301:1131-1139.

27. Montauban van Swijndregt AD, De Lange EE, de Groot E, Ackerstaff RGA: $A n$ in vivo evaluation of the reproducibility of intima-media thickness measurements of the carotid artery segments using B-mode ultrasound. Ultrasound in Medicine \& Biology 1999, 25:323-330.

28. Baumann M, Richart T, Sollinger D, Pelisek J, Roos M, Kouznetsova T, Eckstein HH, Heemann U, Staessen JA: Association between carotid diameter and the advanced glycation end product $\mathrm{N}$-epsiloncarboxymethyllysine (CML). Cardiovasc Diabetol 2009, 8:45.

29. Ito $H$, Komatsu Y, Mifune M, Antoku S, Ishida H, Takeuchi Y, Togane M: The estimated GFR, but not the stage of diabetic nephropathy graded by the urinary albumin excretion, is associated with the carotid intimamedia thickness in patients with type 2 diabetes mellitus: a crosssectional study. Cardiovasc Diabetol 2010, 9:18.

30. Keech AC, Grieve SM, Patel A, Griffiths K, Skilton M, Watts GF, Marwick TH Groshens $\mathrm{M}$, Celermajer DS: Urinary albumin levels in the normal range determine arterial wall thickness in adults with Type 2 diabetes: a FIELD substudy. Diabet Med 2005, 22:1558-1565.

31. Yokoyama H, Aoki T, Imahori M, Kuramitsu M: Subclinical atherosclerosis is increased in type 2 diabetic patients with microalbuminuria evaluated by intima-media thickness and pulse wave velocity. Kidney Int 2004, 66:448-454.

doi:10.1186/1475-2840-9-40

Cite this article as: Lundby-Christensen et al:: Carotid intima-media thickness in individuals with and without type 2 diabetes: a reproducibility study. Cardiovascular Diabetology 2010 9:40.

\section{Submit your next manuscript to BioMed Central and take full advantage of:}

- Convenient online submission

- Thorough peer review

- No space constraints or color figure charges

- Immediate publication on acceptance

- Inclusion in PubMed, CAS, Scopus and Google Scholar

- Research which is freely available for redistribution

Submit your manuscript at www.biomedcentral.com/submit
Biomed Central 